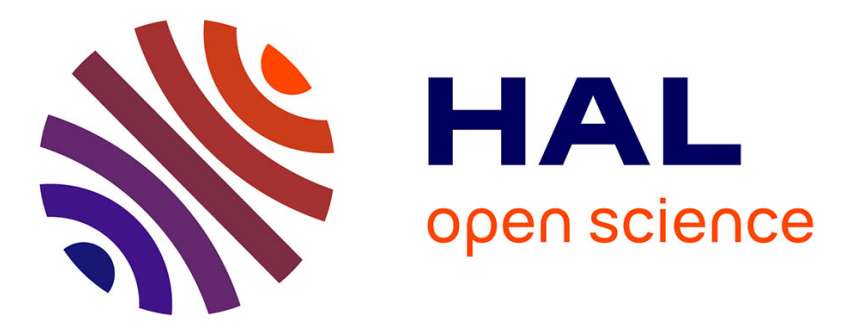

\title{
Effect of carotenoid biosynthesis inhibition on the chlorosome organization in Chlorobium phaeobacteroides strain CL1401
}

J.B. Arellano, J. Psencik, C.M. Borrego, Y.-Z. Ma, Remy Guyoneaud, J. Garcia-Gil, T. Gillbro

\section{To cite this version:}

J.B. Arellano, J. Psencik, C.M. Borrego, Y.-Z. Ma, Remy Guyoneaud, et al.. Effect of carotenoid biosynthesis inhibition on the chlorosome organization in Chlorobium phaeobacteroides strain CL1401. Photochemistry and Photobiology, 2000, 71 (6), pp.715-723. 10.1562/00318655(2000)0710715EOCBIO2.0.CO2 . hal-01843578

\section{HAL Id: hal-01843578 \\ https://hal.science/hal-01843578}

Submitted on 18 Mar 2021

HAL is a multi-disciplinary open access archive for the deposit and dissemination of scientific research documents, whether they are published or not. The documents may come from teaching and research institutions in France or abroad, or from public or private research centers.
L'archive ouverte pluridisciplinaire HAL, est destinée au dépôt et à la diffusion de documents scientifiques de niveau recherche, publiés ou non, émanant des établissements d'enseignement et de recherche français ou étrangers, des laboratoires publics ou privés. 
The definitive version is available at www.blackwell-synergy.com (C) American Society for Photobiology 0031-8655/00 DOI: 10.1562/0031-8655(2000)0710715EOCBIO2.0.CO2 


\section{EFFECT OF CAROTENOID BIOSYNTHESIS INHIBITION ON THE CHLOROSOMAL ORGANISATION AND FUNCTION IN Chlorobium} phaeobacteroides CL1401

J. B. Arellano*1,2, J. Psencik², C. M. Borrego ${ }^{1}$, Y.-Z. Ma $^{2}$, R. Guyoneaud ${ }^{1}$, L.J. Garcia-Gil ${ }^{1}$, T. Gillbro

${ }^{1}$ Laboratory of Microbiology, Institute of Aquatic Ecology. University of Girona, Campus de Montilivi, E-17071, Girona, Spain

${ }^{2}$ Department of Biophysical Chemistry, University of Umeå, S-90187 Umeå, Sweden

Abbreviations: BChl, bacteriochlorophyll; Car, Carotenoid; Chl: Chlorobium; Clf: Chloroflexus; CD, Circular dichroism FMO, Fenna-Matthews-Olson BChl a-protein; GSB, Green Sulfur Bacteria; HBP, 2-Hydroxybiphenyl; Isr, Isorenieratene.

* Corresponding author. PHONE: 34972 418396. FAX: +34 972 418150. E-mail: juan@morgat.udg.es 


\section{ABSTRACT}

We have studied the effect of the absence of carotenoids on the organization of bacteriochlorophylls (BChls) in chlorosomes of Chlorobium (Chl.) phaeobacteroides strain CL1401. Carotenoid-depleted chlorosomes were obtained by means of 2-hydroxybiphenylsupplemented cultures. In the presence of the inhibitor, isorenieratene (Isr) and $\beta$-Isr biosynthesis were inhibited to more than $95 \%$, leading to an accumulation of the colorless precursor phytoene inside the chlorosomes. In addition, there was a $30-40 \%$ decrease in the baseplate BChl $a$ content. The absorption spectrum of the carotenoid-depleted chlorosomes showed a $10 \mathrm{~nm}$ blue shift in the $\mathrm{BChl} e$ Qy absorption peak. Under reducing conditions, a decrease in the $\mathrm{BChl} a / \mathrm{BChl} e$ fluorescence emission ratio was observed in carotenoid-depleted chlorosomes relative to that in control chlorosomes, caused mainly by the decrease in the BChl $a$ content. The steady-state fluorescence emission anisotropy in the $\mathrm{BChl} e$ region dropped from $; 0.24$ for native chlorosomes to $; 0.14$ for carotenoid-depleted ones, indicating reorganization of BChl e. The circular dichroism (CD) signal of the carotenoid-depleted chlorosomes was increased two times in the $\mathrm{BChl} e$ Qy region. A simple model based on the structure proposed was used to explain the observed effects. Carotenoids might affect the angle between the direction of the $\mathrm{BChl} e \mathrm{Qy}$ transition and the axis of the rod. The orientation of $\mathrm{BChl} a$ in the baseplate remains unchanged in carotenoid-depleted chlorosomes, although there is a partial loss of BChl $a$ as a consequence of a decrease in the baseplate size. The carotenoids are most likely rather close to the BChls and appear to be important for the aggregate structure in Chl. phaeobacteroides.

Keywords: Antenna pigments, Bacteriochlorophyll $a$, Bacteriochlorophyll $e$, Carotenoids, Chlorobium phaeobacteroides, Chlorosomes, Energy transfer, GSB, Isorenieratene. 


\section{INTRODUCTION}

Green anoxygenic photosynthetic bacteria comprise two distinct filogenetic groups, the Green Sulfur Bacteria (GSB) and the Multicellular Filamentous Green Bacteria, both characterised by the presence of chlorosomes as main antenna complexes (Blankenship et al. 1995; Olson 1998). The chlorosomes are oblong bodies appressed to the inner side of the cytoplasmic membrane that contain antenna pigments surrounded by a lipid monolayer (Olson, 1998). The pigment composition of chlorosomes consists of highly aggregated antenna bacteriochlorophyll (BChl) $c, d$, or $e, \mathrm{BChl} a$, and carotenoids. The molecular structures of $\mathrm{BChl} c, \mathrm{BChl} d$, and $\mathrm{BChl} e$ are particularly well suited to pigment-pigment interactions (Blankenship et al. 1995 and references therein). Based on these interactions, several models have been proposed to understand their supramolecular arrangement inside chlorosomes (Holzwarth and Schaffner, 1994; Mizoguchi et al. 1996; Buck and Struve, 1996). These models fairly agree in the orientation of the BChl $\mathrm{Q}_{\mathrm{y}}$ transition, which is nearly parallel to the long axis of the chlorosomes. Besides, BChl molecules are tightly packed providing a strong excitonic interaction between their $\mathrm{Q}_{\mathrm{y}}$ transition dipoles. Chlorosomes also contain $\mathrm{BChl} a$, which forms a baseplate on the cytoplasmic membrane side and is supposed to be associated to a $5 \mathrm{kDa}$ polypeptide (Feick and Fuller, 1984). The baseplate BChl $a$ has an important role as an intermediate in the excitation energy transfer from the chlorosome to the cytoplasmic membrane-embedded reaction centre. The stoichiometric ratio between the main chlorosomal $\mathrm{BChl}$ to the baseplate $\mathrm{BChl} a$ ranges from $\sim 25: 1$ in green filamentous bacteria (Feick et al. 1982) to $100: 1$ in green and brown-coloured GSB (Gerola and Olson, 1986; Olson, 1998; Borrego et al. 1999). The excitation energy transfer from the main chlorosomal $\mathrm{BChl}$ to $\mathrm{BChl} a$ has been proved to be strongly dependent on redox-potential of the environment. At reducing conditions, chlorosomes are very strong fluorescent and show a very high efficiency of energy transfer from the main chlorosomal $\mathrm{BChl}$ to $\mathrm{BChl} a$ (Gillbro et al. 1988; Blankenship et al. 1993; Wang et al. 1990). However, at aerobic conditions, the fluorescence emission is very weak and the efficiency of energy transfer decreases to $10-20 \%$ (Wang et al. 1990; Blankenship et al. 1993). Under these latter conditions, either BChl radicals 
(van Noort et al. 1997) or quinones (Frigaard et al. 1997) have been suggested as quenchers of excitation energy in chlorosomes to prevent the reaction centre from photodamage. In GSB there is an additional layer composed of a water-soluble BChl $a$ protein, the so-called FennaMatthews-Olson (FMO) protein, appressed between the baseplate and the cytoplasmic membrane (Blankenship et al. 1995).

Chlorosomes also contain significant amounts of carotenoids (Schmidt 1980). $\beta$ carotene, $\gamma$-carotene, and their derivatives can be detected in chlorosomes of the filamentous bacterium Chloroflexus (Clf.) aurantiacus. Other carotenoids as chlorobactene and $\mathrm{OH}-$ chlorobactene or isorenieratene (Isr) and $\beta$-isorenieratene ( $\beta$-Isr) have been reported in chlorosomes of green- and brown-coloured GSB, respectively (Liaaen-Jensen 1965; Schmidt 1980). The amount of these carotenoids depends on bacterial species, light conditions, and growth phase (Oelze and Golecki 1995). The stoichiometric ratios between the main antenna BChl and carotenoids range from 3.7:1 to 11:1 in Clf. aurantiacus (Frese et al. 1997, Schmidt 1980) and from 6:1 to 21:1 in different species of the genus Chlorobium (Borrego et al. 1999, Schmidt 1980; Frigaard et al. 1997). However, the carotenoid function in chlorosomes remains unclear. In photosynthetic organisms, carotenoids play several functions as (i) light harvesting pigment via singlet state energy transfer, (ii) photoprotection via the quenching of (bacterio)chlorophyll triplet states, (iii) singlet oxygen scavenging, (iv) excess energy dissipation, and (v) structure stabilisation (Frank and Cogdell, 1996). In chlorosomes of Chloroflexus and GSB, different functions for the carotenoids have been suggested. A light harvesting function was proposed by van Dorssen et al. (1986) and Otte et al. (1991). In these works energy transfer from the carotenoid to $\mathrm{BChl} c$ or $e$ was reported to be highly efficient (65\% in Clf. aurantiacus and $90-100 \%$ in Chl. phaeovibrioides). However, recent results of steady-state spectroscopy and femtosecond transient absorption experiments have showed that energy transfer from carotenoids to $\mathrm{BChl} e$ presents a rather low efficiency in chlorosomes of Chl. phaeobacteroides (Aschenbrücker et al. 1999). A photoprotection role via the quenching of BChl triplet states inside the chlorosomes has been proposed by (Pšencík et al. 1994), although 
$100 \%$ efficiency of the quenching of the BChl triplet states could not be observed by those authors, suggesting an asymmetric distribution of the carotenoids in the chlorosomes. Furthermore, carotenoids have been suggested to play another protection role as screen pigments outside of the chlorosomes. In this case, carotenoids can be localised in oleosomes, which increase in number under high light conditions (Beyer et al. 1983). Finally, a structural role has been proposed by Foidl et al. (1997) and Frese et al. (1997) who suggested that in Clf. aurantiacus carotenoids could contribute to the attachment of the chlorosomes to the cytoplasmic membrane via the baseplate.

We have investigated the possible function of carotenoids in chlorosomes of the browncoloured sulfur bacterium Chl. phaeobacteroides strain CL1401. This species was chosen according to its high content of carotenoids (mainly Isr and $\beta$-Isr) and its ecological niche. Chl. phaeobacteroides is usually found in deep water layers where light intensity is very low and enriched in wavelengths of the spectrum between 500 and $600 \mathrm{~nm}$ (Repeta et al. 1989; Borrego et al. 1997). Both features permit to consider this species as the most suitable to study the role of carotenoids within the antenna complexes of GSB. The inhibition of carotenoid biosynthesis using 2-Hydroxybiphenyl and the comparative spectroscopic study between control and carotenoid-depleted chlorosomes have been the strategy followed in this work.

\section{MATERIALS AND METHODS}

\subsection{Organism and growth conditions}

Chl. phaeobacteroides strain CL1401 was grown in standard Pfennig mineral medium (Trüper and Pfennig 1992) in 5-litre glass bottles under continuous stirring. The inoculum was 3\% in all the experiments. Illumination was continuously provided by two Philips SL25 fluorescent lamps giving an average light intensity of $100 \mu \mathrm{mol}$ photons $\mathrm{m}^{-2} \mathrm{~s}^{-1}$ at the surface of the culture bottle.

The incident light was measured between 300 and $1100 \mathrm{~nm}$ using a LI-COR 1800-1W 
spectroradiometer with a remote cosine-corrected receptor (LI-COR 1800-11). Cells were harvested at the beginning of the stationary phase by centrifugation at $16,000 \mathrm{x} g$ for $20 \mathrm{~min}$ at 4 ${ }^{\circ} \mathrm{C}$ in a Sorvall RC5B. Pellets were resuspended in $50 \mathrm{mM}$ Tris- $\mathrm{HCl} \mathrm{pH} 8.0$ and $2 \mathrm{M} \mathrm{NaSCN}$ and stored at $-20{ }^{\circ} \mathrm{C}$ until use.

Inhibition of carotenoid biosynthesis was accomplished using 2-Hydroxybiphenyl (HBP) according to Foidl et al. (1997). For inhibited cultures the mineral medium was supplemented with the appropriate volume of HBP (stock solution: $200 \mathrm{mg} \mathrm{ml}^{-1}$ in ethanol $70 \%$ ) to reach the desired concentration of the inhibitor. A series of preliminary tests were performed in order to check the optimum concentration of HBP for the Chl. phaeobacteroides strain used (data not shown). At concentrations of $20 \mu \mathrm{g} \mathrm{ml}{ }^{-1}$, an inhibition of the carotenoid formation by $>95 \%$ was obtained without substantial effects on photosynthetic growth. Concentrations of HBP above this value clearly inhibited bacterial growth. According to these results the concentration of HBP used throughout the experiments was $20 \mu \mathrm{g} \mathrm{ml}^{-1}$, which was interestingly lower than the $60 \mu \mathrm{g} \mathrm{ml}^{-1}$ used by Foidl and co-workers in Clf. aurantiacus.

\section{Isolation of chlorosomes}

Chlorosomes of Chl. phaeobacteroides grown under control and carotenoid-inhibited conditions were isolated as described by Gerola and Olson (1986). Cells were passed 3 times through an ice-cold French Pressure Cell operating at 20,000 psi. The broken cells were centrifuged at $39,000 \times \mathrm{g}$ for $15 \mathrm{~min}$ to remove intact cells and large debris. The green supernatant containing subcellular photosynthetic fractions was loaded onto a $20-50 \%(\mathrm{w} / \mathrm{w})$ continuous sucrose gradient prepared in $50 \mathrm{mM}$ Tris- $\mathrm{HCl} \mathrm{pH} 8.0$ and $2 \mathrm{M} \mathrm{NaSCN}$ and centrifuged overnight at $218,000 \mathrm{x} g$ in a Sorvall O7D 75B ultracentrifuge. The chlorosome fractions were pooled with a Pasteur pipette and stored at $-80{ }^{\circ} \mathrm{C}$ until use. 
HPLC analysis and pigment stoichiometric determination

Photosynthetic pigments were analysed by reversed-phase HPLC. Pigments were extracted from thawed chlorosomes using acetone:methanol (7:2) (Scharlau, Multisolvent grade). The extract was stored at $-30{ }^{\circ} \mathrm{C}$ during $24 \mathrm{~h}$ and then centrifuged at $16,000 \mathrm{xg}$ for $15 \mathrm{~min}$. The pigment supernatant was dried under a stream of nitrogen and stored at $-30{ }^{\circ} \mathrm{C}$ in the dark. Dry pigments were dissolved in $1 \mathrm{ml}$ of methanol (Scharlau, HPLC grade) and filtered through a $0.2 \mu \mathrm{m}$ Dynagard syringe filter before reversed-phase HPLC analysis. Ammonium acetate (1M) was added to the filtered sample at a final concentration of $10 \%$ as ion pairing agent. Samples were analysed according to Borrego and Garcia-Gil (1994) with the following modification. The run time was enlarged $15 \mathrm{~min}$ at $100 \%$ of solvent $\mathrm{B}$ in order to increase the resolution in the carotenoid elution. Accordingly, the total run time of the HPLC analysis was $75 \mathrm{~min}$. The stoichiometric ratios between pigments in chlorosomes were determined using the spectrumreconstruction method (SRCM) described by Naqvi et al. (1997). Pigments from isolated chlorosomes were extracted in ethanol (Scharlau, Multisolvent Grade) and centrifuged to pellet the unsolubilised proteins. Extracts were kept in the dark until the absorption spectra were recorded. The molar extinction coefficients of BChls and carotenoids used in this study were $62,0001 \mathrm{~mol}^{-1} \mathrm{~cm}^{-1}$ for BChl $a$ in ethanol (Connolly et al. 1982) and 41,000 $1 \mathrm{~mol}^{-1} \mathrm{~cm}^{-1}$ and $107,0001 \mathrm{~mol}^{-1} \mathrm{~cm}^{-1}$ for BChl $e$ and Isr in ethanol, respectively (Borrego et al. 1999).

\section{Steady state spectroscopy}

Absorption spectra were measured using a Beckman DU-70 spectrophotometer with a scan rate of $1200 \mathrm{~nm} \mathrm{~min}{ }^{-1}$. The steady-state fluorescence spectra were recorded using a SPEX Fluorolog 112 fluorometer equipped with Glan-Thompson polarizers and a Hamamatsu R928 red-sensitive multi-alkali photomultiplier. All fluorescence measurements were performed at room temperature after an incubation time of $2 \mathrm{~h}$ in the presence of $16 \mathrm{mM}$ of sodium dithionite to 
ensure reducing conditions. The emission fluorescence anisotropy was determined using the standard expression

$$
r=\frac{F_{V V}-G F_{V H}}{F_{V V}+2 G F_{V H}} \text { and } G=\frac{F_{H V}}{F_{H H}}
$$

where $F$ stands for the emission intensity and the subscripts refer to the vertical or horizontal settings of the excitation and emission polarizers and the correction factor $G$ compensates the different instrument responses for horizontal and vertical polarised light. The optical density of chlorosome samples at the $\mathrm{Q}_{\mathrm{y}}$ band was never higher than $0.2 \mathrm{~cm}^{-1}$ in all fluorescence experiments. Circular dichroism (CD) spectra were recorded using a Jasco J720 apparatus with $1 \mathrm{~nm}$ bandwidth. Background correction was made by subtracting the signal measured using the same cuvette but containing only the $50 \mathrm{mM}$ Tris- $\mathrm{HCl} \mathrm{pH} 8.0$ and $2 \mathrm{M} \mathrm{NaSCN}$ buffer.

\section{RESULTS}

\section{HPLC analysis and pigment stoichiometric ratios}

Both control and carotenoid-depleted chlorosomes of Chl. phaeobacteroides displayed the typical elution pattern for BChl $e$ as described previously (Borrego et al. 1999) (Fig. 1A and 1B). BChl $e$ eluted in two groups of peaks. The first one consisted of a four-peak cluster assigned to the main farnesyl-esterified BChl $e$ homologs (according to Smith (1994) these homologs were identified as $[\mathrm{E}, \mathrm{E}],[\mathrm{Pr}, \mathrm{E}],[\mathrm{I}, \mathrm{E}]$, and $[\mathrm{N}, \mathrm{E}] \mathrm{BChl} e_{\mathrm{F}}$ homologs, eluted in a increasing alkylation order at the C8 position of the porphyrin ring). The second group was composed by several peaks corresponding to minor $\mathrm{BChl} e$ homologs with esterifying alcohols other than farnesyl (Borrego and Garcia-Gil 1994). BChl $a$ eluted at $39.5 \mathrm{~min}$ as a single peak traceable at $770 \mathrm{~nm}$.

The main differences in the pigment composition of both types of chlorosomes laid in the carotenoid content. Control Chlorosomes had a mixture of Isr and $\beta$-Isr as main carotenoid 
pigments. Both carotenoids eluted in the HPLC as a cluster of two peaks, the all trans- and cisisomers. Quantitative analysis of carotenoid isomers in both types of chlorosomes revealed high relative level of cis-isomers of Isr and $\beta$-Isr. A molar all trans- to cis-isomers ratio of 1.4 and 1.3 were determined for control and HBP-treated chlorosomes, respectively. Other carotenoids, as $\beta$-carotene, and other precursors of the Isr biosynthetic pathway were also detected (see legend to Fig. 1 for identification). The chlorosomes from HBP-treated Chl. phaeobacteroides culture showed a severe decrease in the carotenoid content (>95\%) and only traces of Isr and $\beta$ Isr were detected. Interestingly, HBP-treated chlorosomes contained substantial amounts of colourless precursor phytoene $\left(\lambda_{\max }=287 \mathrm{~nm}\right)$ which was absent in chlorosomes from untreated cells (Fig. 1C). This result agrees with those found in carotenoid-inhibited cells of Clf. aurantiacus, which also accumulated phytoene in the presence of HBP (Foidl et al. 1997). Other precursors of carotenoid biosynthesis were hardly detected in HBP-treated chlorosomes. In addition to carotenoid depletion, a decrease of $30-40 \% \mathrm{BChl} a$ was detected too. The SRCM method was used to determine possible changes in the stoichiometric ratios between BChls and carotenoids in both chlorosome preparations. The application of this method gave stoichiometric ratio of $6: 1$ and $>50: 1$ between $\mathrm{BChl} e$ and carotenoids and $\sim 100: 1$ and 150170:1 between $\mathrm{BChl} e$ and $\mathrm{BChl} a$ in control and carotenoid-depleted chlorosomes, respectively.

\section{Absorption and CD spectra}

Room temperature absorption spectra of control and carotenoid-depleted chlorosomes of Chl. phaeobacteroides are shown in Fig. 2. The spectra were normalised to equal concentration of monomeric $\mathrm{BChl} e$, which was determined after converting the $\mathrm{BChl} e$ aggregates into monomers by adding n-propanol to the chlorosome buffered-suspension in a ratio $2: 3$. The $\mathrm{Q}_{\mathrm{y}}$ band of $\mathrm{BChl} e$ has a maximum at $714 \mathrm{~nm}$ in intact native chlorosomes. In carotenoid-depleted chlorosomes the band is blue shifted to $704 \mathrm{~nm}$ and the overall area of the band decreased by approximately $20 \%$. Additional changes can be observed in the $\mathrm{BChl} a$ region (around $790 \mathrm{~nm}$ ) 
which are due to the $30-40 \%$ decrease of BChl $a$ content. There are no obvious changes in the positions of two BChl $e$ peaks of the Soret band. The difference between the two spectra resembles carotenoid absorption spectrum between $350 \mathrm{~nm}$ and $550 \mathrm{~nm}$. However, the contribution of carotenoids to absorption of native chlorosomes must be higher than what shows the difference spectrum (see the Discussion).

The CD spectra of control and carotenoid-depleted chlorosomes normalised to equal concentration of monomeric $\mathrm{BChl} e$ are shown in Fig. 3. Both spectra are conservative within $3 \%$ error. The $\mathrm{CD}$ signal of carotenoid-depleted chlorosomes in $\mathrm{BChl} e \mathrm{Q}_{\mathrm{y}}$ region is approximately twice stronger as that of the control chlorosomes and it is blue shifted similarly as the absorption spectrum. Additional differences can be observed between 450-600 $\mathrm{nm}$.

\section{Emission spectra}

Fluorescence emission spectra of control and carotenoid-depleted chlorosomes of Chl. phaeobacteroides measured under reducing conditions are shown in Fig. 4A. The chlorosomes were excited in their $\mathrm{BChl} e \mathrm{Q}_{\mathrm{y}}$ band to avoid any effect on anisotropy values caused by energy transfer from carotenoids. The isotropic emission spectra are normalised at the $\mathrm{BChl} e$ emission maximum at $742 \mathrm{~nm}$ and $740 \mathrm{~nm}$ for control and carotenoid-depleted chlorosomes, respectively. The difference between emission maxima of both chlorosomal preparation was smaller than 10 nm shift between their absorption maxima (Fig. 2). The fluorescence emission anisotropy spectra (Fig. 4B) of native chlorosomes exhibit constant value of 0.24 within $\mathrm{BChl} e$ emission band which decreases to a value of -0.1 in the $\mathrm{BChl} a$ region. For carotenoid-depleted chlorosomes the corresponding anisotropy values were 0.14 and -0.04 in $\mathrm{BChl} e$ and $\mathrm{BChl} a$ bands, respectively.

\section{DISCUSSION}




\section{Carotenoid inhibition}

Isr and $\beta$-Isr are largely present in chlorosomes of Chl. phaeobacteroides and the stoichiometric ratio between these carotenoids and $\mathrm{BChl} e$ and $a$ has been determined to be $20: 100: 1$ Car:BChl $e: \mathrm{BChl} a$ (Borrego et al., 1999). On the other hand, these carotenoids are present in both conformation all trans and cis in a ratio $\sim 3: 2$. This ratio is a bit surprising when compared to other ratios determined in antenna complexes where cis-carotenoids are not present as LH2 (McDermott et al. 1995) or are present in negligible amounts as such within the bulk lightharvesting complex of Photosystem II (Bialek-Bylka et al. 1998). One reason behind this fact is that in those latter complexes the carotenoids are surrounded by a polypeptidic structure. However it has been stated that it is highly likely that carotenoids in chlorosomes are in the vicinity of the BChls and not near to protein (Frese et al. 1997). If so, it might explain that carotenoids may change more freely their conformation in chlorosomes. The fact that the CD signal between $350 \mathrm{~nm}$ and $450 \mathrm{~nm}$ does not change when control and carotenoid-depleted chlorosome are compared support that carotenoids might not be surrounded by a protein environment. This mixture of carotenoid isomers is a common feature of other green sulfur bacterial species (Borrego, unpublished data). In order to understand the function of these carotenoids in chlorosomes of Chl. phaeobacteroides their biosynthesis were inhibited by means of HBP. The inhibition of carotenoid biosynthesis in Chl. phaeobacteroides resulted in a drastic decrease of the amount of Isr and $\beta$-Isr in the chlorosomes. In HBP-treated cells, the colourless precursor phytoene was accumulated within chlorosomes as previously observed in the case of Clf. aurantiacus by Foidl et al. (1997). This carotenoid can not play neither a light harvesting function nor photoprotection role within the photosynthetic apparatus. In aquatic ecosystems, UV radiation is readily absorbed by the water column and it is not further available for photosynthesis and, most importantly, the triplet energy level of phytoene is too high to quench the BChl triplet states (Frank and Cogdell, 1993). The accumulation of this precursor 
inside chlorosomes might be due to their high lipophilic affinity rather than playing any role in the chlorosomes. In both types of chlorosomes.

\section{BChl $e$ organisation}

The differences between optical spectra of both chlorosomal preparations in the BChl e Qy region suggest that the carotenoid inhibition affects $\mathrm{BChl} e$ organisation. A direct information about the orientation of the transition dipole moments can be obtained from the steady state anisotropy data. Based on two generally accepted assumptions that a) the $\mathrm{BChl} e$ molecules forms an aggregates of cylindrical shape and b) all their dipole moments are distributed symmetrically around the rod axes (i.e. they all contain the same angle $\gamma$ with the long axes of the rod), a the steady state anisotropies can be calculated. It consists of two independent contributions. First, we assume the excitation localised on a single molecule. In this case the anisotropy is determined by energy transfer between the molecules, or more specifically, by an average angle between the transition dipoles of initially and finally excited molecule. For the distribution of the dipoles

$$
\hat{\mu}=\left|\begin{array}{c}
\sin \gamma \cdot \cos \left(i^{*} \alpha\right) \\
\sin \gamma \cdot \sin \left(i^{*} \alpha\right) \\
\cos \gamma
\end{array}\right| \quad \quad \mathrm{i}=1,2 \ldots . \mathrm{n}
$$

(cylindrical coordinates $\alpha, \mathrm{r}, \mathrm{z}$ are used) the depolarisation factor due to the randomisation over the whole rod can be calculated as

$$
d_{1}=\left(\frac{3 \cos ^{2} \gamma-1}{2}\right)^{2}
$$

It should be stressed that all the dipoles are mutually parallel in the direction along the rod, so any change of the excitation in the z-direction does not change the anisotropy value. Anisotropy can be changed only by hopping around the rod.

In the case of excitonically coupled molecules we have to assume yet another contribution to the depolarisation caused by a relaxation from initially delocalised state of the 
aggregate to the state localised on the single molecule. Due to the present disorder we can expect that the excitation energy will be localised shortly after excitation, however the process will certainly affect the anisotropy value. The orientation of the initial state is given by a vector a sum of all monomers transitions dipoles and it is parallel to the long axis of the rod. In this case the angle between absorbing and emitting dipole will be $\gamma$ and we describe the contribution of the process to anisotropy value by a well known general depolarisation factor

$$
d_{2}=\frac{3 \cos ^{2} \gamma-1}{2}
$$

The overall depolarisation is given by a product of all depolarisation factors $\mathrm{d}_{\mathrm{i}}$ :

$$
r=r_{0} \prod_{i}^{m} d_{i}
$$

Except $d_{1}$ and $d_{2}$, there is no other depolarisation processes e.g. due to the energy transfer to neighbouring rod (rods are parallel and all possible orientations of the dipoles are already considered in eq. (2)) or due to energy transfer from carotenoids (BChl $e \mathrm{Q}_{\mathrm{y}}$ band was excited rather than carotenoids). On the other hand, depolarisation could also occur by an overall rotation of the chlorosome. We expect this process to be slow compared to the lifetime of excitation. Most important conclusion is that the value of steady state anisotropy is fully determined by the angle $\gamma$. Using $\mathrm{r}_{0}=0.4$ (theoretical limit) and $\mathrm{r}=0.24$ for native chlorosome an angle $\gamma=19^{\circ}$ is obtained. Similarly, an angle $\gamma=26^{\circ}$ can be calculated for the carotenoid-depleted chlorosomes for $\mathrm{r}=0.14$. If the $\mathrm{d}_{2}$ contribution was omitted, the angles $23^{\circ}$ and $31^{\circ}$ were obtained for control and carotenoid-inhibited chlorosomes, respectively. All these values are in overall agreement with reported angles of $15-30^{\circ}$ (Blankenship et al. 1995).

To check whether these indications are in agreement with differences observed in absorption and CD spectra, we calculated these spectra for both types of chlorosomes. We based our model on the structure of the aggregate proposed by Holzwarth \& Schaffner (1994) for BChl $c$ organisation in Clf. auranticaus. It is a result of quantum mechanical and molecular modelling calculations and it agrees with results of NMR and FDMR (Psencik et al. 1997). In the model the aggregate is formed by the helices of monomers interacting via hydrogen 
bonding. From the point of view of excitonic interactions between the monomers the aggregate can be considered as strongly interacting linear stacks arranged into tubular rod.

The parameters used for calculations are illustrated in Figure X. The orientation of the transition moments given by equation (1) was used. In the original model of Holzwarth \& Schaffner the values of $x=0.76 \mathrm{~nm}, \mathrm{z}=0.68$, and $\gamma=30^{\circ}$ were determined. In our calculations we change the angle $\gamma$ to $19^{\circ}$ or $26^{\circ}$, respectively and recalculated other parameters so that $\mathrm{Mg}-\mathrm{Mg}$ distance $(\mathrm{m}$; determined by $\mathrm{OH} \ldots \mathrm{O}=\mathrm{C}<$ interaction) and $\mathrm{Mg} . . \mathrm{OH}(\mathrm{p})$ remain the same as in the original model and the new structures are still consistent with chemical bounded helices and excitonically coupled linear stacks. The proposed model can not represent definitive description of the system due to the lack of structural information for $\mathrm{BChl} e$ aggregates, however, we believe it can provide good basis for qualitative estimation of the expected effects on the spectra The absorption and CD spectra were calculated in the point-dipole approximation and only Qy transitions were considered. Interactions between the rods were not considered. The dipole moment of BChl $e$ monomer was estimated to be $\mu^{2}=23$ debeye ${ }^{2}$ from comparison of the absorption spectra of monomeric $\mathrm{BChl} e$ and $\mathrm{BChl} a$. For BChl $a$ in acetone the dipole moment is known to be 68 debeye $^{2}$ (Monshouwer et al. 1997). Low values of relative dielectric constants values of were used $(\varepsilon=1.0-1.2)$ as there is almost no protein present in the chlorosome. Saturation of the red shift of absorption maxima was observed for aggregates of length $\sim 15$ monomers. The spectra calculated for $15 \times 15$ aggregate with angle $\gamma$ equal to $19^{\circ}$ and $26^{\circ}$, respectively and dressed with Gaussian envelopes of $\Gamma_{\text {hom }}=300 \mathrm{~cm}^{-1}$, are shown on Fig. Ya. The fact that position of maxima fit very well with experimental values should be regarded rather as coincidence due to extent of approximations made. More importantly, the spectra predict the 10 nm difference between the absorption maxima of native and carotenoid-inhibited chlorosomes. Both spectra have equal intensities, as they represent sum of identical number of the dipoles. Fig $\mathrm{Yb}$ shows calculated $\mathrm{CD}$ spectra. In addition to the spectral shift the spectra corresponding to $\gamma=26^{\circ}$ exhibit two fold increase of the CD signal. 
To get an agreement between the widths of experimental and calculated spectra, an introducing of $\sim 400 \mathrm{~cm}^{-1}$ distribution of the monomer energies (diagonal disorder) and/or an increase of the number of monomers per aggregate is necessary. As the result, the whole spectrum is broadened and the lowest states match emission wavelengths (not shown). In measured absorption spectra of the carotenoid-deficient chlorosome the $\mathrm{BChl} e \mathrm{Q}_{\mathrm{y}}$ band intensity was by $20 \%$ lower than in the native sample. In a monomeric form of $\mathrm{BChl} e$ the $\mathrm{Q}_{\mathrm{y}}$ band is responsible for less than $15 \%$ of the total oscillator strength. However, the total oscillator strength should be conserved for monomers and aggregates in both types of chlorosomes. The relative higher intensity of the $\mathrm{Q}_{\mathrm{y}}$ band of $\mathrm{BChl} e$ of control chlorosomes (normalised to the same number of monomers - Fig 2) thus implies that the 'transfer' of oscillator strength from Soret band to $\mathrm{Q}_{\mathrm{y}}$ band is higher in these aggregates. As the total area corresponding to absorption of aggregates (in wavenumbers) should be conservative, the contribution of carotenoids to absorption of native chlorosomes must be higher than what shows the difference spectrum. The same conclusion can be made on the basis of comparison of the extinction coefficients. If we normalise the calculated absorption and CD spectra according to experimental absorption spectra, the agreement between intensities of calculated and measured CD spectra becomes worse and we have to assume that the higher intensity of the CD signal of carotenoid-deficient chlorosomes is increased by some accompanying reason. Here we should mention that for HBP treated chlorosomes of Clf. auranticaus Frese et al. (1997; see below) observed increase of the CD signal without any changes in the absorption spectra. As the CD spectra are not conservative within the Qy region, but they are conservative within the whole spectrum, it indicates a 'transfer' of the rotational strength between different states, similarly as in absorption spectra. The mechanism might be coupling of $\mathrm{Q}_{\mathrm{y}}$ manifold to higher states of hypochromic effect.

\section{BChl $a$ organisation}


Except the partial loss of the pigment in carotenoid-deficient chlorosomes, the only pronounced spectroscopical difference in $\mathrm{BChl} a$ region was observed in emission anisotropies. In the following we will show that these changes may be explained as a consequence of changes in $\mathrm{BChl} e$ organisation: As there is a direct energy transfer from $\mathrm{BChl} e$ to $\mathrm{BChl} a$, we can used the general equation (3) to calculate an angle between the transition moments of both pigments, providing we will use anisotropy values measured in $\mathrm{BChl} e$ region as $\mathrm{r}_{0}$. In this way we can calculate an angle $66^{\circ}$ for control sample and $59^{\circ}$ for the carotenoid-depleted chlorosomes. As the angles between the $\mathrm{BChl} e$ transition dipole and the $\mathrm{z}$ axis were calculated to be $19^{\circ}$ and $26^{\circ}$, respectively, an identical value of $85^{\circ}$ can be calculated for the angle between $\mathrm{BChl} a$ transition moment and the long axis of chlorosome for both control and carotenoid-inhibited chlorosomes. Similar orientation of BChl $a$ molecules was determined also for baseplate BChl $a$ in Clf. aurantiacus (van Dorssen et al. 1986). This result suggest that orientation of $\mathrm{BChl} a$ molecules is not affected by the carotenoid inhibition and is close to perpendicular to the long axis of the chlorosome. The lose of $30-40 \%$ of $\mathrm{BChl} a$ content in carotenoid inhibited is considered in next section.

\section{Role of carotenoid}

All steady state spectra suggest that carotenoid deficiency affect properties of BChl $e$ in Chl. phaeobacteroides. This in contrast with situation for green filamentous Clf. aurantiacus, for which the carotenoid-deficient chlorosomes were obtained by means of HBP treatment earlier (Foidl et al. 1997). No changes in the position of $\mathrm{BChl} c \mathrm{Q}_{\mathrm{y}}$ absorption maximum in their carotenoid-depleted chlorosomes were observed (Frese et al. 1997). Authors concluded that organisation of BChls is independent of the presence of carotenoids. The composition and function of green sulfur bacteria chlorosomes differs significantly from those of green filamentous bacteria, for instance by size or by redox-dependent quenching of chlorosomal excitation (Blankenship 1995), which was not observed for Clf. aurantiacus. On the basis of our results we believe that the role of carotenoids may be different in green sulfur bacteria as well. 
Previously carotenoids triplet states were observed in chlorosomes of green sulfur bacteria at reducing conditions (Psencik 1994). As the Car's triplet states can be populated only via T-T energy transfer, this means that carotenoids must be in very close contact with at least a portion of both chlorosomal and baseplate BChls. This close contact may result in interaction between the carotenoids and BChls affecting the formation of the BChl aggregates. The 'action' of carotenoids is indeed necessary at the time of aggregate formation as the structure of BChls is not changed after hexane treatment of chlorosomes, which completely removes carotenoids. (Ying-Zhong Ma et al., submitted) As the carotenoids are not able to quench all the triplet states of chlorosomal BChl's (Psencik et al 1994) it is also possibly that not all of the aggregates are affected, but mainly those close to the baseplate where is the highest probability of accumulation of excitation energy and triplet state formation. It should be noted that similar spectral shifts of BChl $e$ bands were observed as a result of growing the bacteria at different light conditions, which led also to changes of carotenoid content. Another indication that significant part of the carotenoids is close to the baseplate is based on the observation that $\mathrm{BChl}$ $a$ was partially removed after hexane treatment of chlorosomes, which completely removes carotenoids (Ying-Zhong MA et al., submitted) Further Foidl et al. (1997) and Frese et al. (1997) observed a slightly higher BChl $c$ to BChl a ratios in Clf. aurantiacus when grown in the presence of HBP, and proposed that carotenoids might function as a molecular glue, allowing the attachment of chlorosomes to the cytoplasmic membrane via the baseplate. Under our experimental growth conditions, we observed a $30-40 \%$ loss of $\mathrm{BChl} a$ in the carotenoiddepleted chlorosomes, which might support it. Presence of carotenoids close to baseplate could favour the photoprotection of baseplate $\mathrm{BChl} a$. In both samples, $\mathrm{BChl} a$ emission maximum was at $808 \mathrm{~nm}$, however, the relative yield of BChl $a$ emission decreased by $43 \%$ in carotenoiddepleted chlorosomes. This decrease can be attributed 1) mainly to the 30-40\% loss of BChl $a$ observed in pigment analysis and 2) due to possible enhancement of $\mathrm{BChl} e$ emission as a consequence of the loss of $\mathrm{BChl} a$ which is an acceptor of $\mathrm{BChl} e$ excitation. Coloured carotenoids are well known to play some role in the assembly of (B)Chls to the photosynthetic antenna. For instance, a functional light harvesting 2 complex (LH2) in purple bacteria needs 
the presence of carotenoids. Zurdo et al. (1993) described that the removal of LH2 carotenoids from Rhodobacter capsulatus by selective extraction with light petroleum was accompanied by bleaching of the B800 $\mathrm{Q}_{\mathrm{y}}$ band, which resembled the LH2 of the carotenoidless mutant of Rhodobacter sphaeroides. The partial loss of BChl $a$ in the carotenoid-depleted chlorosomes of GSB strongly supports that carotenoids have some structural role on the assembly of a functional baseplate BChl $a$. Electron microscopy studies carried out in control and HBP-treated cells showed striking differences in the chlorosomes morphology. The control cells had oblong chlorosomes and the section of the attached surface of the baseplate to the cytoplasmic membrane was the leading dimension, while, the chlorosomes of HBP-treated cells were rounds and the attached surface of the baseplate was smaller (A. Martínez, personal communication).. These findings are in agreement with the suggestion pointed out by Foidl and collaborators and point out that not only could carotenoids be a molecular glue, but also could play a structural role in the enlargement of the baseplate to place a greater number of BChl $a$ molecules and facilitate the energy transfer from $\mathrm{BChl} e$ to $\mathrm{BChl} a$.

In conclusion, we have shown that the inhibition of the carotenoids synthesis in Chl. phaeobacteroides effect the $\mathrm{BChl} e \mathrm{Q}_{\mathrm{y}}$ spectral properties, which can be qualitatively explained by a structural changes in the arrangement of $\mathrm{BChl} e$ aggregates, affecting mainly angle between the transition dipole moment and rod axis. BChl $a$ orientation is not alternated, although there is a partial loss of it as a consequence of a decrease of the baseplate size. According to our results we propose that in Chl. phaeobacteroides, carotenoids might play a structural role in fixing and maintaining the structure of the baseplate as to ensure an efficient energy transfer between $\mathrm{BChl} e$ and $\mathrm{BChl} a$. Besides, carotenoids might be potentially involved in a mechanism by which GSB protect BChl $a$ or BChl $e$ nearby the baseplate, and subsequently its reaction centres, from overwhelming energy funnelled by the chlorosome. By this mechanism, carotenoids are revealed as an important constituent of green bacterial chlorosomes, providing a plausible explanation of its ubiquitous and significant occurrence in the antenna complexes of these photosynthetic microorganisms. 


\section{Acknowledgements}

This study was funded by the European Community (Contract No FMRX-CT96-0081). Dr.

Juan B. Arellano and Prof. C.A. Abella were partially supported by the Spanish Ministry of Education and Culture (Ref. BIO96-1229-002-01). JB Arellano is very grateful to the ESF for awarding him a short-term fellowship to Umeå University.

\section{REFERENCES}

Aschenbrücker J, Ma Y-Z, Miller M and Gillbro T (1999) The role of carotenoids in energy transfer of chlorosomes of Chlorobium phaeobacteroides: steady-state spectroscopy and femtosecond transient absorption study. Submitted to Biochemistry.

Beyer P, Falk H and Kleining H (1983) Particulate fractions from Chloroflexus aurantiacus and distribution of lipids and polyprenoid forming activities. Arch Microbiol 134: 60-63.

Bialek-Bylka GE, Sakano Y, Mizoguchi T, Shimamura T, Phillip D, Koyama Y and Young AJ (1998) Central-cis isomers of lutein found in the major light-harvesting complex of photosystem II (LHC IIb) of higher plants. Photosynth Res 56: 255-264.

Blankenship RE, Cheng P, Causgrove TP, Brune DC, Wang SH, Choh JU and Wang J (1993) Redox regulation of energy transfer efficiency in antennas of green photosynthetic bacteria. Photochem Photobiol 57: 103-107.

Blankenship RE, Olson JM and Miller M (1995) Antenna complexes from green photosynthetic bacteria. In: Blankenship RE, Madigan MT and Bauer CE (eds). Anoxygenic photosynthetic bacteria, Advances in Photosynthesis, Vol II, pp 399-435. Kluwer Academic Publishers, Dordrecht. 
Borrego CM and Garcia-Gil LJ (1994) Separation of bacteriochlorophyll homologues from green photosynthetic sulfur bacteria by reversed-phase HPLC. Photosynth Res 41: 157-163.

Borrego CM, Garcia-Gil LJ, Vila X, Cristina JB, Figueras JB and Abella CA (1997) Distribution of bacteriochlorophyll homologs in natural populations of brown-coloured phototrophic sulfur bacteria. FEMS Microbiol Ecol 24: 301-309.

Borrego CM, Arellano JB, Abella CA, Gillbro T and Garcia-Gil LJ (1999) The molar extinction coefficient of bacteriochlorophyll $e$ and the pigment stoichiometry in Chlorobium phaeobacteroides. Photosynth Res in press.

Buck DR, and Struve WS (1996) Tubular exciton models for BChl $c$ antennae in chlorosomes from green photosynthetic bacteria. Photosynth Res 48: 367-377.

Connolly JS, Samuel EB and Janzen F (1982) Effects of solvent on the fluorescence properties of bacteriochlorophyll $a$. Photochem Photobiol 36: 565-574.

Feick RG, Fitzpatrick M and Fuller RC (1982) Isolation and characterization of cytoplasmic membranes and chlorosomes from the green bacterium Chloroflexus aurantiacus. J. Bacteriol 150: 905-915.

Feick RG and Fuller RC (1984) Topography of the photosynthetic apparatus of Chloroflexus aurantiacus. Biochemistry 23: 3693-3700.

Foidl M, Golecki JR and Oelze J (1997) Phototrophic growth and chlorosome formation in Chloroflexus aurantiacus under conditions of carotenoid deficiency. Photosynth Res 54: 219226. 
Frank HA and Cogdell RJ (1993) Photochemistry and function of carotenoids in photosynthesis. In: Young A. and Britton G. (eds). Carotenoids in photosynthesis, pp.252-326. Chapman and Hall, London.

Frank HA and Cogdell RJ (1996) Carotenoids in photosynthesis. Photochem Photobiol 63: 257264.

Frese R, Oberheide U, van Stokkum I, van Grondelle R, Foild M, Oelze J and van Amerongen H (1997) The organization of bacteriochlorophyll $c$ in Chloroflexus aurantiacus and the structural role of carotenoids and protein. Photosynth Res 54: 115-126.

Frigaard NU, Takaichi S, Hirota M, Shimada K and Matsuura K (1997) Quinones in chlorosomes of GSB and their role in the redox-dependent fluorescence studied in chlorosomelike bacteriochlorophyll $c$ aggregates. Arch Microbiol 167: 343-349.

Gerola PD and Olson JM (1986) A new bacteriochlorophyll $a$-protein complex associated with chlorosomes of GSB. Biochim Biophys Acta 848: 69-76.

Gillbro T, Sandström Å, Sunström V and Olson JM (1988) Picosecond energy transfer kinetics in chlorosomes and bacteriochlorophyll a-proteins of Chlorobium limicola. In: Olson JM, Ormerod JG, Amesz J, Stackebrandt E and Trüper HG (eds) Green Photosynthetic Bacteria, pp 91-96. Plenum Press, New York.

Holzwarth AR and Schaffner K (1994) On the structure of bacteriochlorophyll molecular aggregates in the chlorosomes of green bacteria. A molecular modelling study. Photosynth Res 41: $225-233$. 
Koyama Y (1995) Natural selection of carotenoid configurations by light-harvesting complexes and reaction centers: configuracional dependence of excited state properties. In: Mathis P (ed) Photosynthesis; From light to Biosphere, Vol IV, pp 83-86. Kluwer Academic Publishers, Dordrecht.

Koyama Y, Kuki M, Anderson PO and Gillbro T (1996) Singlet excited states and the lightharvesting function of carotenoids in photosynthesis. Photochem Photobiol 63: 243-256. Liaaen-Jensen S (1965) Bacterial carotenoids. XVIII. Aryl carotenoids from Phaeobium. Acta Chem. Scand. 19: 1025-1030.

Monshouwer R, Abrahamsson M, van Mourik F and van Grondelle R (1997) Superrradiance and exciton delocalisation in bacterial-harvesting systems. J. Phys. Chem. B 101: 7241-7248.

Mizoguchi TK, Matsuura K, Shimada K and Koyama Y (1996) The structure of the aggregate form of bacteriochlorophyll c showing the $\mathrm{Q}_{\mathrm{y}}$ absorption above $740 \mathrm{~nm}$ : a ${ }^{1} \mathrm{H}-\mathrm{NMR}$ study. Chem. Phys. Lett. 260: 153-158.

Naqvi KRN, Melo TB and Bangar Raju B (1997) Analysing the chromophore composition of photosynthetic systems by spectral reconstruction: application to the light-harvesting complex (LHC II) and the total pigment content of higher plants. Spectrochem Acta A: Molecular and Biomolecular spectrosc 53: 2229-2234.

Oelze J and Golecki JR (1995) Membranes and chlorosomes of green bacteria: Structure, composition, and development. In: Blankenship RE, Madigan MT and Bauer CE (eds). Anoxygenic photosynthetic bacteria, Advances in Photosynthesis, Vol II, pp 259-278. Kluwer Academic Publishers, Dordrecht. 
Olson JM (1998) Chlorosome organization and function in green photosynthetic bacteria. Photochem Photobiol 67: 61-75.

Otte SCM, van der Heiden JC, Pfennig N and Amesz J (1991) A comparative study of the optical characteristics of intact cells of photosynthetic GSB containing bacteriochlorophyll $c, d$ or $e$. Photosynth Res 28: 77-87.

Pearlstein RM (1991) Theoretical interpretation of antenna spectra. In: Scheer H (ed). Chlorophylls, pp 1047-1078. CRC Press, Boca Raton.

Psencik P, Searle GFW, Hala J and Schaafsma T (1994) Fluorescence detected magnetic resnance (FDMR) of green sulfur photosynthetic bacteria Chlorobium sp.. Photosynth Res 40: $1-10$.

J. Psencik, T. J. Schaafsma, G. F. W. Searle and J. Hala (1997) Fluorescence detected magnetic resonance of monomers and aggregates of bacteriochlorophylls of green sulfur bacteria Chlorobium sp. Photosynth. Res. 52 83-92.

Repeta DJ, Simpson DJ, Jorgensen BB and Jannasch HW (1989) Evidence for anoxygenic photosynthesis from distribution of bacteriochlorophylls in the Black sea. Nature 342: 69-72.

Schmidt K (1980) A comparative study on the composition of chlorosomes (Chlorobium vesicles) and cytoplasmic membranes from Chloroflexus aurantiacus OK-70-fl and Chlorobium limicola f. thiosulfatophilum strain 6230. Arch Microbiol 124: 21-31.

Smith KM (1994) Nomenclature of bacteriochlorophylls c, d, and e. Photosynth. Res. 41: 2326. 
Trüper HG and Pfennig N (1992) The family Chlorobiaceae. In: Balows A, Trüper HG, Dworkin M, Harder W and Schleifer KH (eds) The Prokaryotes. A Handbook on the Biology of Bacteria: Ecophysiology, Isolation, Identification, Applications, pp 3583-3592, $2^{\text {nd }}$ edition. Springer-Verlag, Berlin.

van Dorssen RJ, Vasmel H and Amesz J (1986) Pigment organization and energy transfer in the green photosynthetic bacterium Chloroflexus aurantiacus. II. The chlorosome. Photosynth Res 9: $33-45$.

van Noort PI, Zhu Y, LoBrutto R and Blankenship RE (1997) Redox effects on the excited-state lifetime in chlorosomes and bacteriochlorophyll c oligomers. Biophys J 72: 316-325.

Wang J, Brune DC and Blankenship RE (1990) Effects of oxidants and reductants on the efficiency of excitation transfer in green photosynthetic bacteria. Biochim Biophys Acta 1015: 457-463.

Zurdo J, Fernandez-Cabrera C and Ramirez JM (1993) A structural role of the carotenoid in the light-harvesting II-protein of Rhodobacter capsulatus. Biochem J 290: 531-537. 


\section{FIGURE LEGENDS}

Fig. 1. HPLC elution profiles recorded at $453 \mathrm{~nm}$ of (A) control chlorosomes and (B) HBPtreated chlorosomes of Chl. phaeobacteroides. Insert in B shows a magnification in the carotenoids elution region. (C) Comparison of HPLC traces recorded at $287 \mathrm{~nm}$ of control (solid line) and HBP-treated chlorosomes (dashed line). Peak identification: (1) [E,E]BChl $e_{\mathrm{F}}$; (2) $[\mathrm{Pr}, \mathrm{E}] \mathrm{BChl} e_{\mathrm{F}} ;(3)[\mathrm{I}, \mathrm{E}] \mathrm{BChl} e_{\mathrm{F}} ;(4)[\mathrm{N}, \mathrm{E}] \mathrm{BChl} e_{\mathrm{F}} ;(5-13)$ secondary $\mathrm{BChl} e$ homologs esterified with alcohols different from farnesyl; (14) all-trans Isr; (15) 15-cis Isr; (16) tentatively 9-cis Isr; (17) all-trans $\beta$-Isr; (18) 15-cis $\beta$-Isr; (19) all-trans $\beta$-carotene; (20) 15 -cis $\beta$-carotene; (21) phytoene; (22) tentatively cis phytoene; $\left(^{*}\right)$ precursors. BChl $e$ homologs were named according to Smith (1994).

Fig. 2. Absorption spectra at room temperature of control chlorosomes (solid line) and HBPtreated chlorosomes (dashed line) of Chl. phaeobacteroides. Chlorosomes were suspended in 50 $\mathrm{mM}$ Tris- $\mathrm{HCl} \mathrm{pH} 8.0$ and $2 \mathrm{M} \mathrm{NaSCN}$. The spectra have been normalised to have equal content of $\mathrm{BChl} e$ (see text for more details).

Fig. 3. CD spectra at room temperature of control chlorosomes (solid line) and HBP-treated chlorosomes (dashed line) of Chl. phaeobacteroides. Chlorosomes were suspended in $50 \mathrm{mM}$ Tris- $\mathrm{HCl} \mathrm{pH} 8.0$ and $2 \mathrm{M} \mathrm{NaSCN}$. The spectra have been normalised to have equal content of $\mathrm{BChl} e$ (see text for more details).

Fig. 4. (A) Fluorescence emission spectra of control chlorosomes (solid line) upon excitation at $695 \mathrm{~nm}$ and of HBP-treated chlorosomes (dashed line) upon excitation at $710 \mathrm{~nm}$. The fluorescence emission spectra were normalised at the $\mathrm{BChl} e$ emission peak. (B) Fluorescence emission anisotropy of control chlorosomes (solid line) upon excitation at $695 \mathrm{~nm}$ and of HBP- 
treated chlorosomes (dashed line) upon excitation at $710 \mathrm{~nm}$. Chlorosomes were suspended in $50 \mathrm{mM}$ Tris- $\mathrm{HCl} \mathrm{pH} \mathrm{8.0,2} \mathrm{M} \mathrm{NaSCN}$ and $16 \mathrm{mM}$ dithionite and incubated for at least $2 \mathrm{~h}$.

Fig 5. Parameters used in calculation of absorption and CD spectra: angle between the rod axis and the dipole moment of the monomer (g); $\mathrm{Mg}-\mathrm{Mg}$ distance between the stacks (x); $\mathrm{Mg}-\mathrm{Mg}$ distance between the monomers within the stack (z) and shift between the stacks (s). $\mathrm{Mg}-\mathrm{Mg}$ distance within the helix (m) and $\mathrm{Mg} \cdots \mathrm{OH}$ distance between helices (p) were kept constant as in the original model (3) while other parameters were recalculated for g 519 and 268, respectively.

Fig. 6. Calculated absorption spectra (a) and CD spectra (b) for $15 \times 15$ aggregate with $\gamma=19^{\circ}$, $\mathrm{x}=0.5 \mathrm{~nm}, \mathrm{~s}=0.54 \mathrm{~nm}, \mathrm{z}=0.9 \mathrm{~nm}\left(\right.$ solid line) and $\gamma=26^{\circ} ; \mathrm{x}=0.67 \mathrm{~nm} ; \mathrm{s}=0.59 \mathrm{~nm} ; \mathrm{z}=0.78$ $\mathrm{nm}$ (dotted line). 
Figure 1

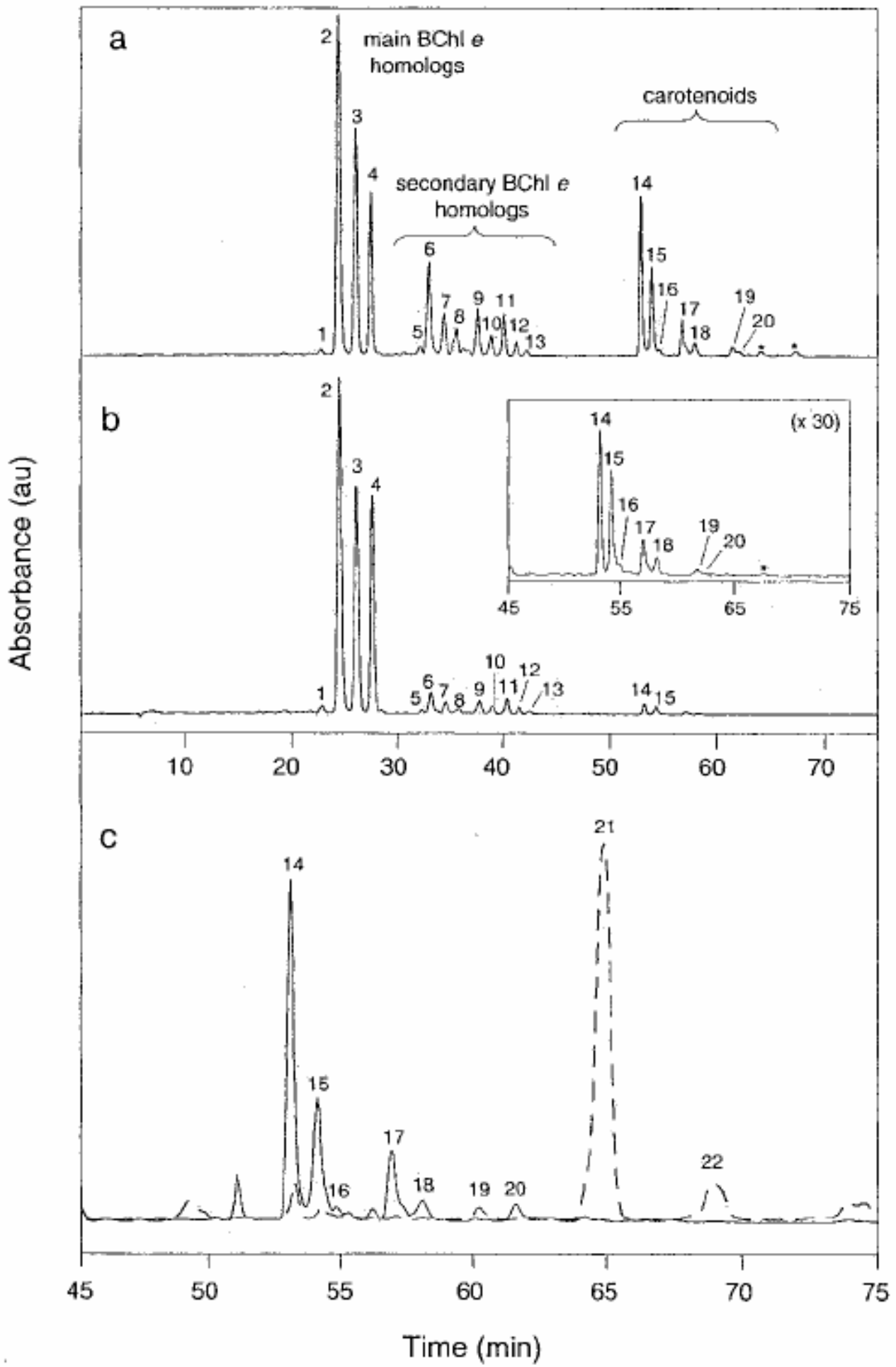


Figure 2

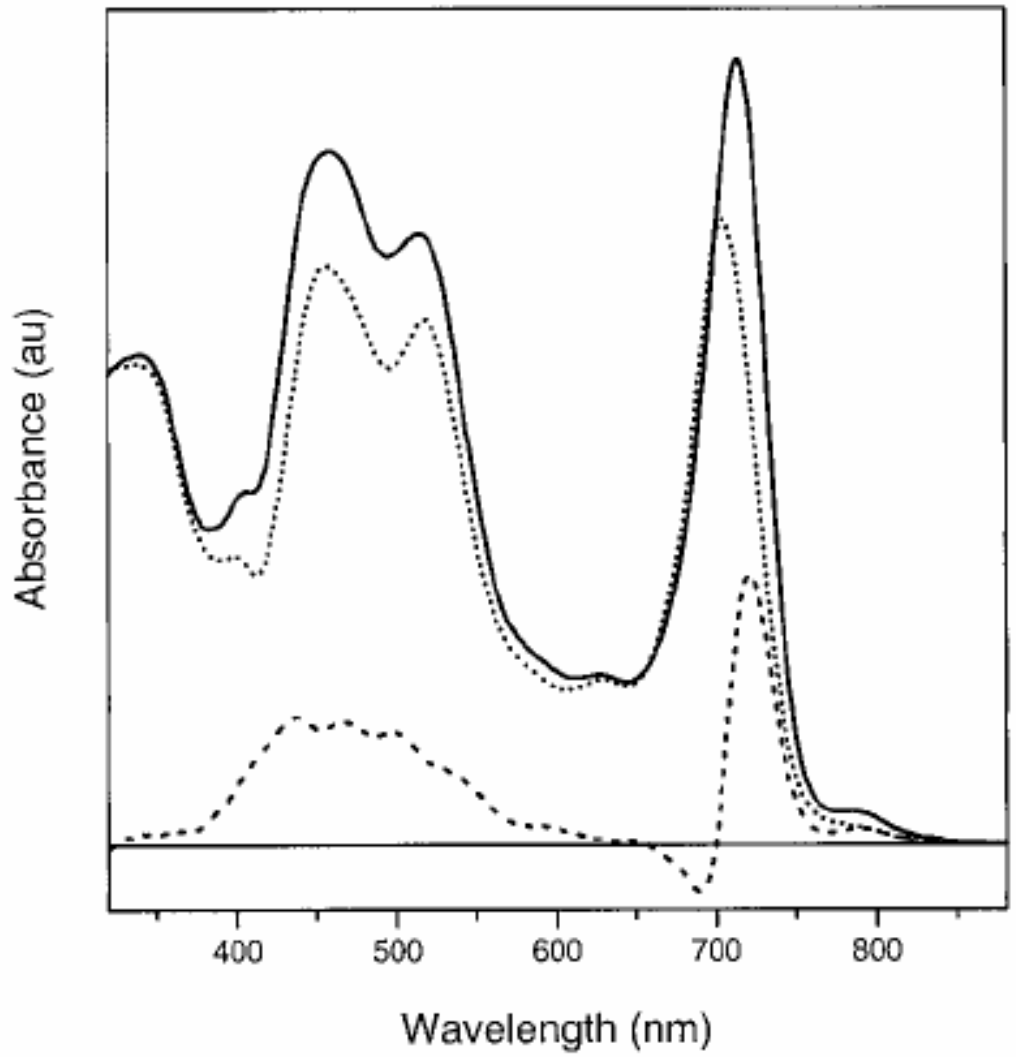


Figure 3

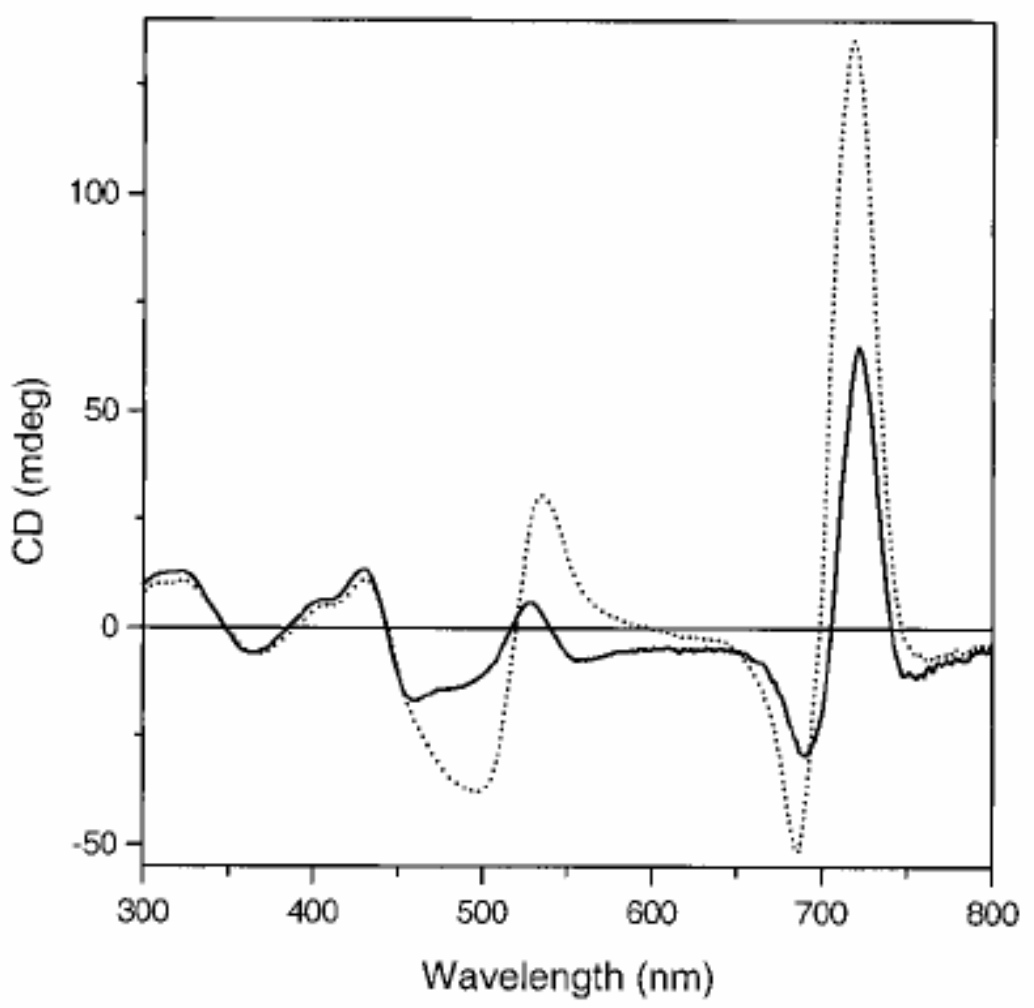


Figure 4
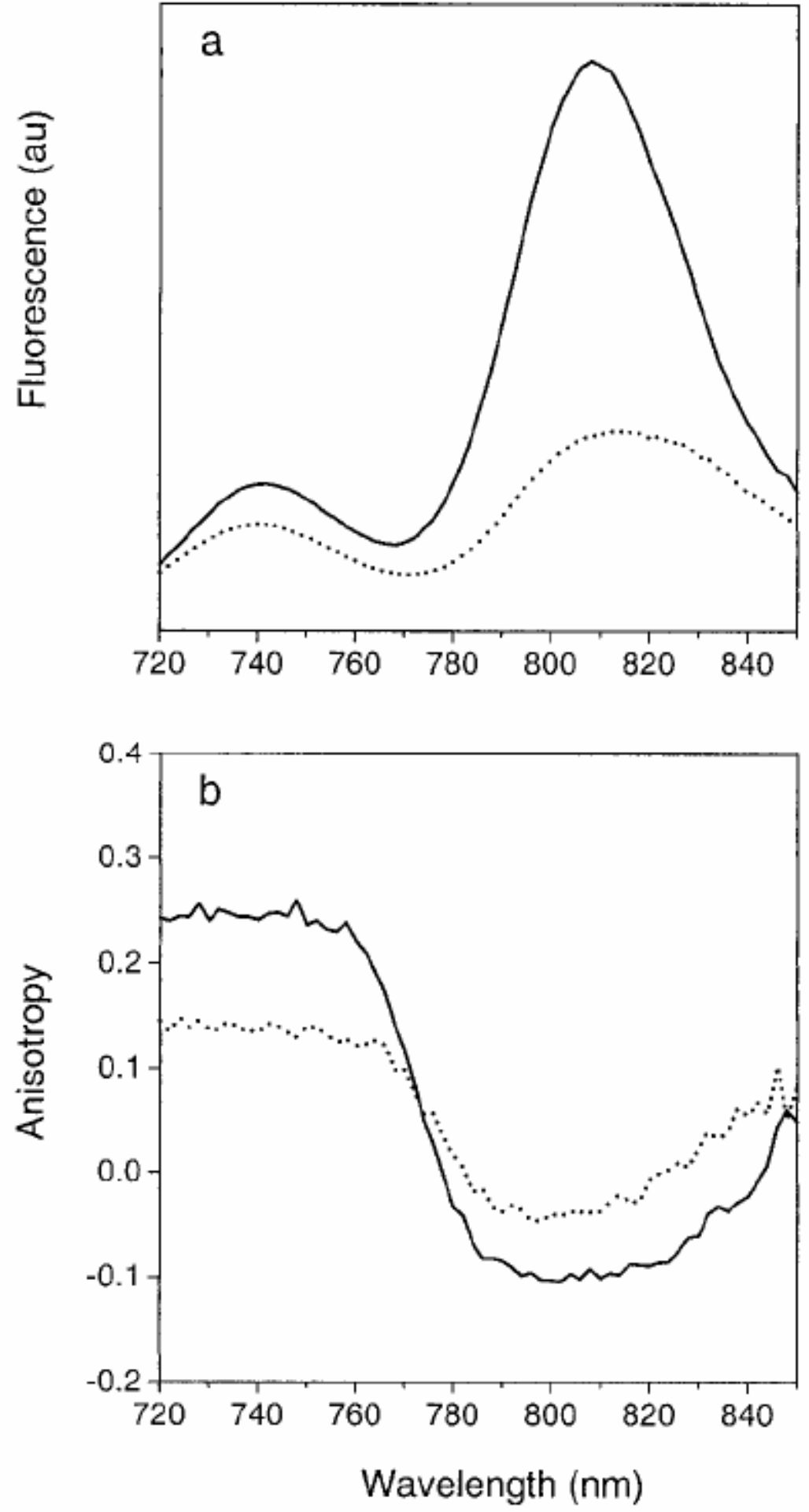
Figure 5

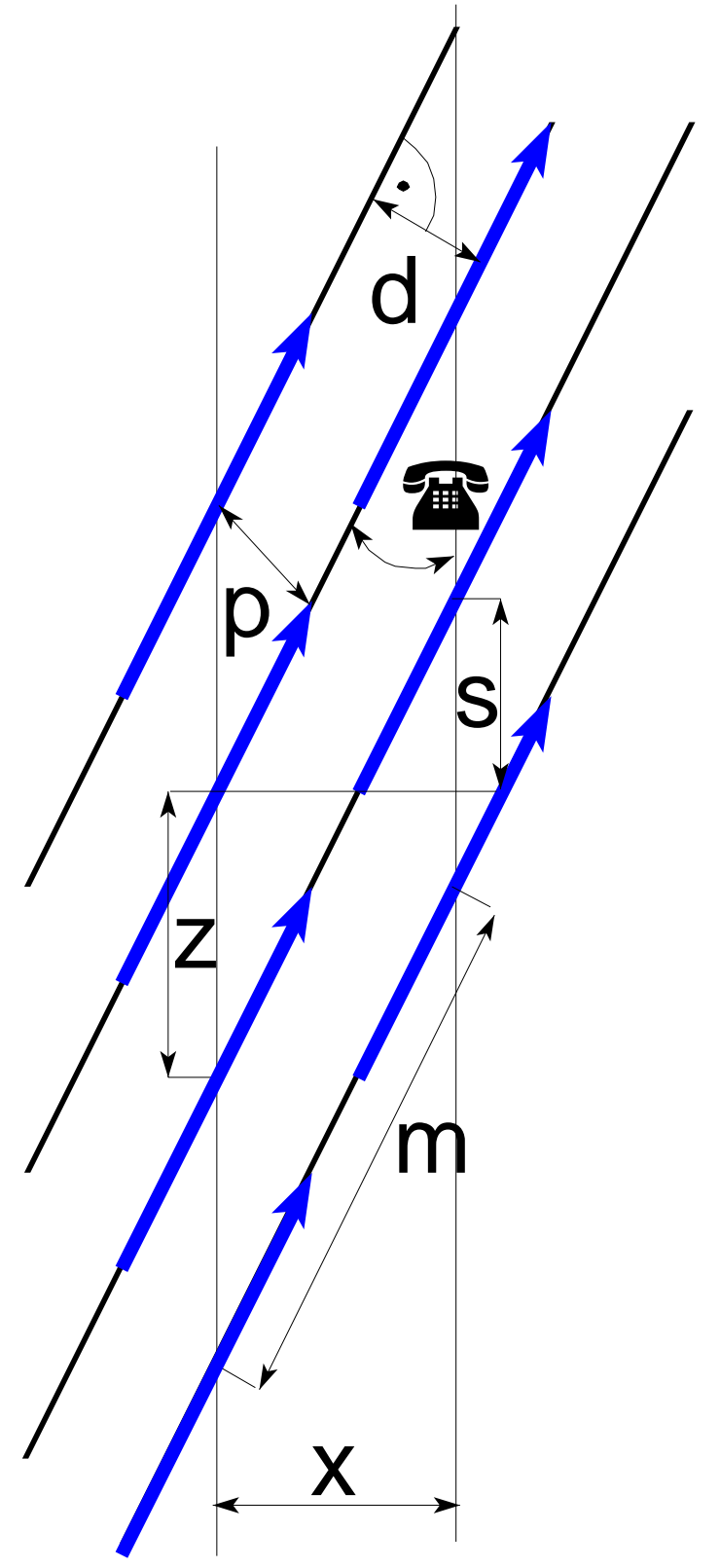


Figure 6
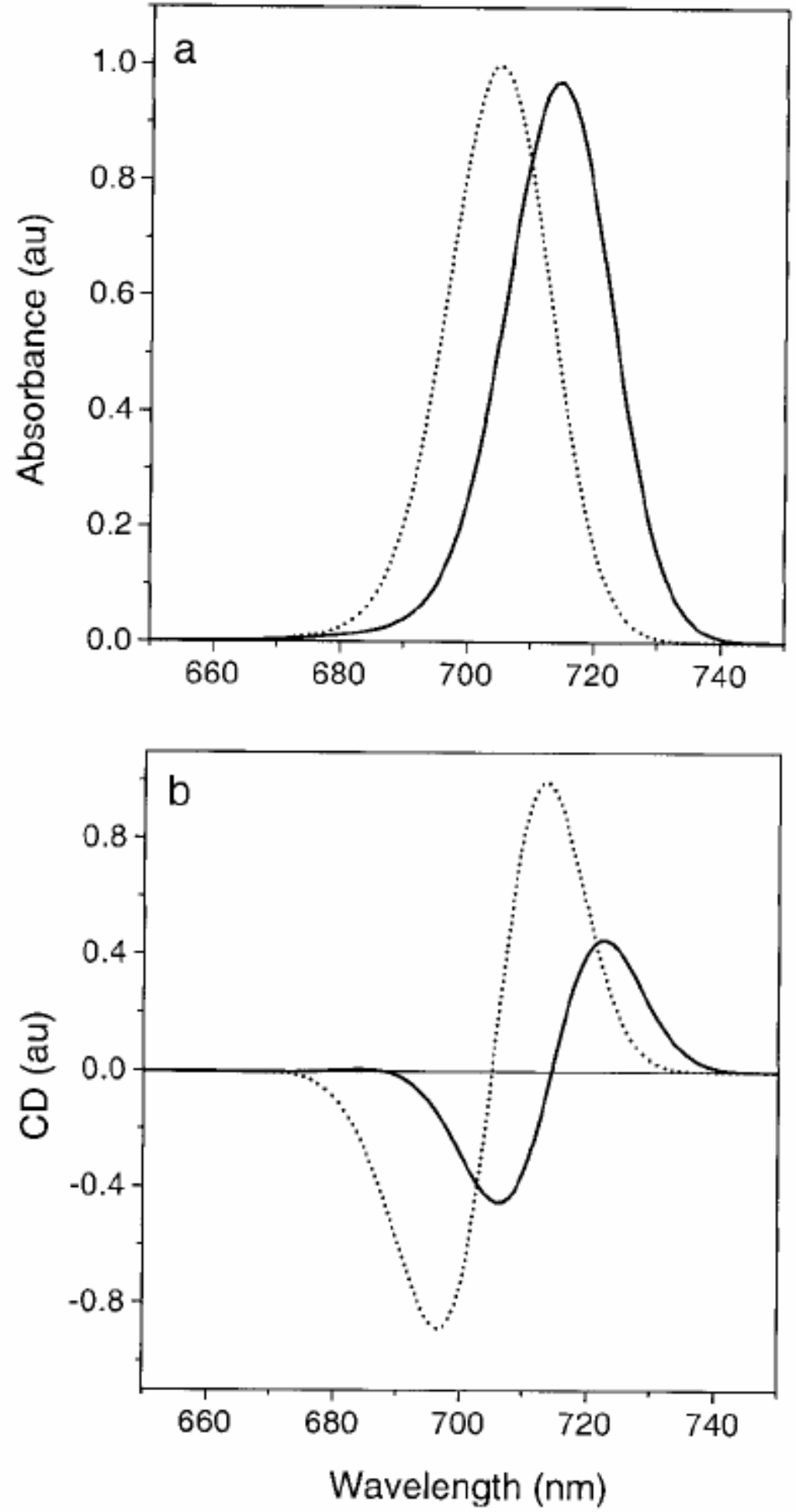